American J. of Engineering and Applied Sciences 2 (2): 451-455, 2009

ISSN 1941-7020

(C) 2009 Science Publications

\title{
Utilization of Soft Wood Wastes as a Feed Stock to Produce Fuel Ethanol
}

\author{
${ }^{1}$ Adnan M. Khalil, ${ }^{2}$ Ali F. Al-Shawabkeh, ${ }^{3}$ Ayman S. Mazahreh, \\ ${ }^{4}$ Mohmmad S. Al-Damanhoory and ${ }^{5}$ Jihad M. Quasem \\ ${ }^{1}$ Depatment of Chemical Engineering, Faculty of Engineering Technology, \\ Al-Balqa Applied University, P.O. Box 15008, Amman 11134, Jordan \\ ${ }^{2}$ Department of Basic Sciences, Faculty of Engineering Technology, \\ Al-Balqa Applied University, P.O. Box 15008, Amman 11134, Jordan \\ ${ }^{3}$ Department of Applied Science, Princes Alia University College, \\ Al-Balqa Applied University, P.O. Box 941941, Amman, 11194 Jordan \\ ${ }^{4}$ Depatment of Basic Sciences, Princess Alia University College, \\ Al-Balqa Applied University, P.O. Box 941941, Amman 11194, Jordan \\ ${ }^{5}$ Department of Medical Allied Sciences, Zarka University College, \\ Al-Balqa Applied University, P.O. Box 313, Zarka 1310, Jordan
}

\begin{abstract}
Problem statement: The current research investigated the utilization of soft wood waste as a feedstock to produce a value-added product-fuel ethanol. Approach: The main issue in converting soft wood waste to fuel ethanol is the accessibility of the polysaccharides for breaking down into monosaccharides. This study focused on the use of steam as the pretreatment method. The governing factors for the effectiveness of steam pretreatment are steam temperature and retention times. Following steam pretreatment, soft wood waste was subjected to acid hydrolysis. The sugars released by acid hydrolysis were fermented in series chemical reactions that convert sugars to ethanol. The fermentation reaction was caused by yeast, which feed on the sugars. Results: Steam pretreatment was able to improve both glucose yields from acid hydrolysis and ethanol yields from fermentation. The results obtained from this study showed that steam pretreated soft wood waste are a heterogeneous material. So biomass goes through a size-reduction step to make it easier to handle and to make the ethanol production process more efficient. Steam treatment on soft wood waste increased the hydrolysis of cellulose by acid hydrolysis. Following $24 \mathrm{~h}$ of diluted or concentrated acid hydrolysis, a maximum cellulose conversion of $20.5 \%$ was obtained. Similarly, sugars to ethanol conversions were improved by steam treatment. Maximum sugar to ethanol conversion of $40.7 \%$ was observed. Conclusion: It was recommended that the hydrolysis process be done for $40 \mathrm{~min}$ to obtain the maximum sugars yield in a reasonable period of time.
\end{abstract}

Key words: Fuel ethanol, wastes, soft wood, agriculture residue, biomass crops

\section{INTRODUCTION}

Ethanol is now the most important renewable fuel in terms of volume and market value ${ }^{[6]}$. Ethanol is referred to as an "oxygenated" fuel because of its higher oxygen content. The incomplete combustion of gasoline produces carbon monoxide $\left(\mathrm{CO}_{2}\right)$, hydrocarbons and particulates. The addition of ethanol or other oxygenated fuels to gasoline reduces $\mathrm{CO}$ production by providing more oxygen and promoting complete combustion. A study showed a $14 \%$ CO reduction as a result of oxygenated fuel usage in winter.
Energy and environmental issues are among the major concerns facing the global community today ${ }^{[7]}$. In view of the environmental benefits and the decreasing supply of crude oil, industry has been moving towards greater ethanol fuel usage. Automobile manufacturers such as ford, Honda and Chrysler have begun to manufacture limited supplies of E85 (15\% ethanol with 85\% gasoline) and E95 (5\% ethanol with 95\% gasoline) cars.

Currently, about $90 \%$ of ethanol is produced from wood. However, research is being done using other sources of biomass, such as sawdust, soft wood and wastepaper ${ }^{[2]}$.

Corresponding Author: Ayman S. Mazahreh, Department of Applied Science, Princes Alia University College, Al-Balqa Applied University, P.O. Box 941941, Amman, 11194 Jordan 
The current research investigates the utilization of soft wood waste as a feedstock to produce a valueadded product-fuel ethanol. The feedstock consists of cellulosic fibers, including soft wood, agriculture residues, biomass crops and lignocellulosic wastes. The three main chemical constituents are cellulose, hemicellulose and lignin ${ }^{[5]}$.

Cellulose and hemicellulose are polysaccharides of primarily fermentable sugars, glucose and xylose respectively. Hemicellulose also includes small fractions of arabinose, galactose and mannose, all of which are fermentable as well ${ }^{[3]}$.

Lignin is a complex polymer, which provides structural in planets. It makes up $10-24 \%$ by weight of biomass. It remains as residual material after the sugars in the biomass have been converted to ethanol. It contains a lot of energy and can be burned to produce steam and electricity for the biomass-to-ethanol process $^{[4]}$.

The main issue in converting soft wood waste to fuel ethanol is the accessibility of the polysaccharides for breaking down (de-polymerizing) into monosaccharides. This study focused on the use of steam as the pretreatment method.

The governing factors for the effectiveness of steam pretreatment are steam, temperature and retention time.

Following steam pretreatment, soft wood waste was subjected to acid. The sugars released by acid hydrolysis were fermented in series chemical reactions that convert sugars to ethanol. The fermentation reaction is caused by yeast, which feed on sugars.

Cell wall constituents: As a whole, soft wood waste should be considered a lignocellulosec material. Lignocellulosic materials consist of there main groups of polymers: Hemicellulose and lignin. Cellulose and hemicellulose are polysaccharides of the desired fermentable sugars. Cellulose is a polymer of glucose, a 6-carbon sugar. Hemicellulose is more diverse, consisting of a mixture of 5-carbon and 6-carbon sugars such as xylose, mannose glucose, arabinose, galactose and uronic acids (Table 1 and 2). Lignin is a phenolic polymer and therefore cannot be utilized by ethanol fermenting microorganisms ${ }^{[5]}$.

The basic structures, organization and interactions between these molecules largely determine the physical and chemical characteristics of the overall plant. Some extractives such as waxes and lipids are also present in cell walls, but serve no structural purpose.

Another component, made up of inorganic materials such as calcium, potassium and silicone.
Table 1: Typical levels of cellulose, hemicellulose and lignin in biomass (www.bio.org)

\begin{tabular}{ll}
\hline Component & Percent dry weight \\
\hline Cellulose & $40-60$ \\
Hemicellulose & $20-40$ \\
Lignin & $10-25$ \\
\hline
\end{tabular}

Table 2: results for $2000 \mathrm{~g}$ wastepaper sample which pretreated

\begin{tabular}{llll}
\hline Material & $\begin{array}{l}\text { Six-carbon } \\
\text { sugars }(\%)\end{array}$ & $\begin{array}{l}\text { Five-carbon } \\
\text { sugars }(\%)\end{array}$ & $\begin{array}{l}\text { Lignin } \\
(\%)\end{array}$ \\
\hline Hardwoods & $39-50$ & $18-28$ & $15-28$ \\
Softwoods & $41-57$ & $8-12$ & $24-27$ \\
As residues & $30-42$ & $12-39$ & $11-29$ \\
\hline
\end{tabular}

Research overview and objectives: The general objective of this research is to investigate, at the laboratory scale, the use of soft wood and paper wastes for the production of fuel ethanol. Soft wood waste, composition, biomass pretreatment and fermentation are addressed with an emphasis on the effects of pretreatment on ethanol production.

The specific objectives are:

- To characterize the chemical composition of raw material and steam pretreated soft wood waste and wastepaper

- To apply and study the effects of steam pretreatment on biomass sugar recovery, acid hydrolysis yields and ethanol yields

- To ferment the released sugars to ethanol using bacteria and yeast

\section{MATERIALS AND METHODS}

The clinker samples were supplied by Cement Industries of Malaysia Limited (CIMA Limited) located at Bukit Keteri, Perlis, Malaysia. The samples were taken from a various place in kiln that have different section of temperature zone during production of cement. The samples were taken from four sections, which are section A ( $15 \mathrm{~m}$ from end of kiln), section B (10 $\mathrm{m}$ from end of kiln), section C (5 m from end of kiln) and section D (at the end of kiln). Each sample was divided into three for different analysis. Samples were prepared according to ASTM procedure before investigated under optical microscope and SEM JEOL 6460 LA with $12 \mathrm{kV}$ acceleration volt. Samples for microstructure analysis need to be molded in resin and polished down to $0.05 \mu \mathrm{m}$. Samples were also etched with nital for $20 \mathrm{~s}$ before analyzed using optical microscope and SEM.

Screening and size homogenization: Two different stocks were used in the experiments; sawdust and waste paper. 
It was observed that the sawdust consists of different sizes, big wooden parts and many undesirable particles like some small metal object, so it was homogenized by passing through a screening process and 25 mesh number screen was used.

The second stock-wastepaper-was passed through a process which cut the sheets of many kinds of paper and turned it into small thin parts and any colorized papers, or any papers which contain dyes was avoided because of the bad effect in the next processes Which the paper will be applied, like hydrolysis, fermentation.

Steam pretreatment of the stocks: The stocks were treated inside a high-pressure steam unit; every different stock was treated separately. Liquid hot water pretreatment uses pressure to keep water in a liquid state at elevated temperatures. Flow-through processes pass the liquid water at elevated temperatures through the cellulosic material ${ }^{[7]}$.

First, the sawdust stock was treated and it was fed as batches, every batch contains $2000 \mathrm{~g}$ of screened sawdust, the pressure was constant during all the treatment process for all the batches. The pressure and temperature, which were applied, are 2 atm and $150^{\circ} \mathrm{C}$; they remained constant.

The retention time for every batch was different, the first batch was treated for half an hour and the final batch was treated for $4 \mathrm{~h}, 8$ batches were used, $30 \mathrm{~min}$ difference between every two batches.

Every batch was hold on a metal grid inside the unit, then the high pressure steam will penetrate the particles causing the wood fibers to be separated and get away all the lignin fibers which surrounding the cellulose fibers.

The wastepaper was also treated but at low retention time due to the difference in properties, so 8 batches every batch is $2000 \mathrm{~g}$ were used. First batch was treated for 10, 20, $40 \mathrm{~min}$ and the final batch for $80 \mathrm{~min}, 10 \mathrm{~min}$ difference between every two batches.

A simple diagram for the steam pretreatment unit is shown in Fig. 1.

Hydrolysis process of the pretreated stocks: Every pretreated batch then passes through a hydrolysis process using diluted $(2 \mathrm{~N})$ hydrochloric acid ${ }^{[7]}$.

- Sawdust stock: Every batch, which equaled 2000 g and pretreated at different retention times, as mentioned before is partition to 8 sections, every one equals $250 \mathrm{~g}$, then every section has subjected to diluted hydrochloric acid with $2 \mathrm{~N}$ concentration at different retention times, the first section was subjected to the diluted acid for 10, $20 \mathrm{~min}$ and the last section for $40 \mathrm{~min}, 5 \mathrm{~min}$ difference between every two batches:

- Temperature is remained constant at $95^{\circ} \mathrm{C}$

- Wastepaper stock: Different retention times, as mentioned before is partition to 8 sections, every one equals $250 \mathrm{~g}$, then every section has subjected to diluted hydrochloric acid with $2 \mathrm{~N}$ concentration at different retention times, the first section was subjected to the diluted acid for $10.20 \mathrm{~min}$ and the last section for $40 \mathrm{~min}, 5 \mathrm{~min}$ difference between every two batches:

- Temperature is remained constant at $95^{\circ} \mathrm{C}$

- After finishing the hydrolysis process, all the solid and liquid material (remaining slurry) is subjected to filtration

- Sugar solution which is prepared by dissolving the sugar obtained by the hydrolysis process in $200 \mathrm{~mL}$ boiling water (the dissolved oxygen will be driven out), then few drops of a diluted acid as hydrochloric acid is added to adjust the $\mathrm{pH}$, meanwhile the optimum $\mathrm{pH}$ range is 6 . Then the activated yeast is mixed with the previous prepared solution inside the fermenter and agitator is switched on to start blending, the temperature is remained at the range $(23 \sim 26)^{\circ} \mathrm{C}$ :

- Every batch requires $120 \mathrm{~h}$ (5 days)

- After the fermentation process finished, the liquor conveyed to a reflux distillation

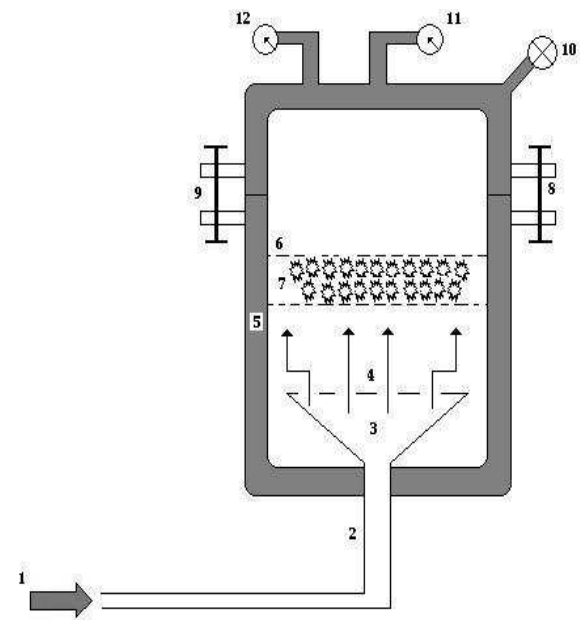

Fig. 1: The high-pressure steam pretreatment unit. (1): High-pressure steam from the boiler; (2): Stainless steel pipe; (3): Distribution grid; (4): Steam; (5): Stainless steel vessel; (6): Holding grid; (7): Sample (sawdust or paper-wastes); (8 and 9): Opening-closing section of the unit; (11): Pressure indicator; (12): Temperature indicator 


\section{RESULTS}

According to the results, which are gained form the experiments, producing ethanol from waste-wood (sawdust, wastepaper) depends on many factors, which must be taken in consideration.

\section{DISCUSSION}

The effect of the sort of stocks: Results show that the final ethanol yield obtained from the wastepaper stocks (which consists of pure cellulose fibers only) is more than the ethanol yield obtained form the sawdust stock.

The effect of pretreatment retention time: The retention time of steam pre-treating of the sawdust samples with high pressure and temperature steam does not show any results until the retention time reaches $210 \mathrm{~min}$, this due to the mechanical effect of the steam pretreatment which completely separate thee wood fibers from each other (Cellulose, Hemicellulose, Lignin) and simplify the next hydrolysis process which mainly depends on the accessibility to the cellulose and memicellulose fibers ${ }^{[1]}$.

So the $210 \mathrm{~min}$ is the minimum value, which must start with under the same conditions $\left(150^{\circ} \mathrm{C}, 2 \mathrm{~atm}\right)$.

The results of the wastepaper were totally different, all the retention time values-starting with 10 min until reaching $80 \mathrm{~min}$ shows slight increment of the ethanol yield as the retention time of the steam pretreatment increases. The optimum steam pretreatment retention time is $20 \mathrm{~min}$.

The effect of pressure and temperature: Temperature and pressure have a significant effect during the steam pretreatment process. Temperature also has a good effect during the hydrolysis process; so using diluted acid solution must be companied with elevated temperatures $\left(95^{\circ} \mathrm{C}\right)$, which increase the accessibility of the acid ions to the glycosidic bonds by reducing the viscosity of the acid solution and increase the rate of reaction to cleave the bonds.

The effect of hydrolysis retention time: Hydrolysis retention time is considered one of the most important factors that effect the final ethanol yield. At the initial stages of the hydrolysis reaction, larger pore volumes do correspond to faster reaction rates. However, after limited hydrolysis, the reaction rate slows down considerably. The glycosidic bonds most susceptible to hydrolysis are those either at the surfaces or in the inside regions of cellulose. Rapid hydrolysis rates reflect hydrolysis activity in these regions and can be seen as a decrease in the Degree of Polymerization (DP).
Table 3: Results for $2000 \mathrm{~g}$ sawdust sample which pretreated

\begin{tabular}{lrrr}
\hline Steam pretreated sample for 210 min: & & & \\
Hydrolysis retention time at $95^{\circ} \mathrm{C}(\mathrm{min})$ & 10.00 & 20.00 & 40.00 \\
Sugar yield after the Hydrolysis process $(\mathrm{g})$ & 6.32 & 9.96 & 10.71 \\
Sugar recovery (\%) & 2.53 & 3.98 & 4.28 \\
Ethanol after the fermentation process (mL) & 2.60 & 4.50 & 4.70 \\
Ethanol yield (\%) & 32.54 & 35.65 & 34.62 \\
Steam pretreated sample for $\mathbf{2 4 0}$ min: & & & \\
Hydrolysis retention time at $95^{\circ} \mathrm{C}(\mathrm{min})$ & 10.00 & 20.00 & 40.00 \\
Sugar yield after the Hydrolysis process (g) & 5.02 & 8.78 & 11.03 \\
Sugar recovery (\%) & 2.00 & 3.50 & 4.41 \\
Ethanol after the fermentation process (mL) & 1.90 & 3.70 & 4.60 \\
Ethanol yield (\%) & 29.86 & 33.25 & 32.90 \\
\hline
\end{tabular}

Table 4: Results for $2000 \mathrm{~g}$ wastepaper sample which pretreated

\begin{tabular}{|c|c|c|c|}
\hline \multicolumn{4}{|l|}{ Steam pretreated sample for $10 \mathrm{~min}$ : } \\
\hline Hydrolysis retention time at $95^{\circ} \mathrm{C}(\mathrm{min})$ & 10.00 & 20.00 & 40.00 \\
\hline eld after the hydrolysis process ( $\mathrm{g}$ ) & 8.49 & 19.83 & 25.61 \\
\hline$(\%)$ & 3.40 & 7.93 & 10.24 \\
\hline Ethat & 2.70 & 7.80 & 11.40 \\
\hline Ethar & 25.09 & 31.00 & 35.12 \\
\hline \multicolumn{4}{|l|}{ Steam pretreated sample for $20 \mathrm{~min}$} \\
\hline Hydrolusis retention time at $95^{\circ} \mathrm{C}(\mathrm{mi}$ & 0 & & \\
\hline & & & 34.20 \\
\hline 19 & 6.25 & 10.60 & 13.68 \\
\hline L) & 4.70 & 11.70 & 20.10 \\
\hline Ethan & 23.77 & 34.80 & 46.37 \\
\hline \multicolumn{4}{|l|}{ Steam pretreated sample for $40 \mathrm{mi}$} \\
\hline & 10.00 & 20.00 & 40.00 \\
\hline & 16.38 & 32.80 & 38.67 \\
\hline & 6.55 & 13.12 & 15.47 \\
\hline th & 5.20 & 15.30 & 22.20 \\
\hline Ethan & 25.05 & 36.80 & 45.30 \\
\hline \multicolumn{4}{|l|}{ Steam pretreated sa } \\
\hline & 10.00 & 20.00 & 40.00 \\
\hline Igar & 19.31 & 46.68 & 48.11 \\
\hline ugar & 7.70 & 18.67 & 19.30 \\
\hline thanol after the fermentation process (mL) & 8.30 & 23.10 & 25.10 \\
\hline thanol yield $(\%)$ & 33.90 & 39.00 & 41.1 \\
\hline
\end{tabular}

The sawdust samples' results show that after $20 \mathrm{~min}$, the hydrolysis retention time has no effect on the sugars yield and increasing the retention time which results with slightly increment of the sugars yield. Economically, it is desired that the hydrolysis retention time will be carried out at $20 \mathrm{~min}$ because increasing the time will not effect the sugars yield. This is shown in Table 3.

The wastepaper results show that after $20 \mathrm{~min}$, the hydrolysis retention time has no effect also on the sugars yield and the sugars yields remain constant. This is shown in Table 4.

\section{CONCLUSION}

Ethanol has been regarded as one of the main liquid transportation fuels that can take the place of fossil fuel. Energy and environmental issues are among the major concerns facing the global community today this paper 
suggest promising techniques worthy of further exploration for commercialization this techniques.

\section{Suggest:}

- $210 \mathrm{~min}$ is the minimum value, which must start with under the same conditions $\left(150^{\circ} \mathrm{C}, 2 \mathrm{~atm}\right)$

- The optimum steam pretreatment retention time is $20 \mathrm{~min}$

Economically, it is desired that the hydrolysis retention time will be carried out at 20 min because increasing the time will not effect the sugars yield.

Increasing the retention time more than $20 \mathrm{~min}$ will not effect the sugars yield in both sawdust samples and wastepaper samples, so it is recommended that the hydrolysis process be done for $40 \mathrm{~min}$ to obtain the maximum sugars yield in a reasonable period of time.

\section{REFERENCES}

1. Saddler, J.N., H.H. Brownell, L.P. Clermont, N. Levitin, 1982. Enzymatic hydrolysis of cellulose and various pretreated wood fractions. Biotechnol. Bioeng., 24: 1389-1402. http://www.ncbi.nlm.nih.gov/pubmed/18546431

2. Chang, V.S., W.E. Kaar, B. Burr and M.T. Holtzapple, 2001. Simultaneous saccharification and fermentation of time-treated biomass. Biotechnol. Lett., 23: 1327-1333. http://cat.inist.fr/?aModele $=$ afficheN\&cpsidt $=1412$ 1758
3. Carvalheiro, F., S.F. Talita, and C.D. Luís et al., 2008. Wheat straw auto hydrolysis: Process optimization and products characterization. Applied Biochem. Biotechnol., 153: 84-93. DOI: 10.1007/s12010-008-8448-0

4. Li, A., Antizar-Ladislao and M. Khraisheh, 2007. Bioprocess Biosyst. Eng., 30: 189-196. DOI: 10.1007/soo 449-007-0114-3

5. Taher Zaheh, M.J. and K. Karimi, 2008. Pretreatment of lignocellulosic wastes to improve ethanol and biogas production: A review. Int. J. Molsci, 9: 1621-1651. DOI: 10.3390/ijmsgog1621

6. Hu, G., J.A. Heitmann and O.J. Rojas, 2008. Feedstoch pretreatment strategies for producing Ethanol From wood, Bark and forest Residues. BioResources, 3: 270-294. http://www.ncsu.edu/bioresources/BioRes_03/Bio Res_03_1_0270_Hu_HR_Feedstock_Pretreatment. pdf

7. Cuerra, A., I. Filpponen, L.A. Lucia, C. Saquing, S. Bamberger and D.S. Argyropoulos, 2006. Toward a better understanding of the lignin isolation process from wood. J. Agric. Food Chem., 54: 5939-5947. http://cat.inist.fr/?aModele $=$ afficheN\&cpsidt $=1800$ 9082 